\title{
GRAZING DURATION STUDIES ON LUCERNE
}

\author{
G. P. Cosgrove
}

(M. Agr.Sc., Lincoln College, University of Canterbury)

A grazing study was conducted on irrigated Wairau lucerne (Medicago sativa L.) 'during summer and autumn using mixed-aged ewes. Two treatments were imposed: grazing durations of 3 and 12 days, with similar spells to the early flower stage of growth between successive grazings. This was carried out over two grazing and regrowth cycles.

Weekly measurements of regrowth following grazing showed that, for both periods, regrowth following a 12-day grazing duration was more rapid than regrowth following a 3-day duration, in the early stages. The superiority developed initially was maintained until the early flower stage. Yields of dry matter were 4170 and $2435 \mathrm{~kg} \mathrm{DM} /$ ha for each regrowth period following grazing for 12 days. Corresponding yields following grazing for 3 days were 4000 and $2350 \mathrm{~kg}$ DM/ha.

Concurrent with the second grazing and regrowth periods, a cutting trial was set up to simulate the long and short grazing durations. The long simulated grazing duration depressed dry matter yield at the early flower stage compared with the short simulated duration, whereas actual grazing demonstrated the superiority in yield of a long duration. Therefore, conclusions that would have been drawn from a cutting trial alone were different from those drawn from the grazing trial, demonstrating that care must be exercised in interpreting results of simulated grazing trials. Dry matter yields of regrowth following cutting were considerably lower than the yields obtained following grazing.

The patterns of grazing in a long and a short grazing duration were compared. Sheep grazing for 12 days ate more of the available dry matter than sheep grazing for 3 days. The difference occurred in the early stage of a long grazing duration when the lower stocking rate resulted in less competition for the most palatable plant parts, the apices and leaves. For both grazing durations the rate of dry matter consumption declined as the duration progressed because of a decline in digestibility and an increase in the percentage of unpalatable stem material in the available dry matter.

In vitro digestibility measurements showed that the digestibility of the leafless stalk at the end of grazing for 12 days was equivalent to lucerne hay, having declined $20 \%$ since the start of grazing. The digestibility of lucerne declined only $10 \%$ during regrowth to the late flower stage in autumn.

Observations during regrowth following grazing indicated a stimulator-y effect on plant growth and vigour of dung and/or urine. This was not apparent on areas receiving cutting management. Measurements of plant nitrogen in such areas showed that levels had been raised by animal returns. This is discussed, together with other work indicating that nitrogen fixation in lucerne may not always be adequate for maximum growth. 